This item was submitted to Loughborough's Institutional Repository (https://dspace.lboro.ac.uk/) by the author and is made available under the following Creative Commons Licence conditions.

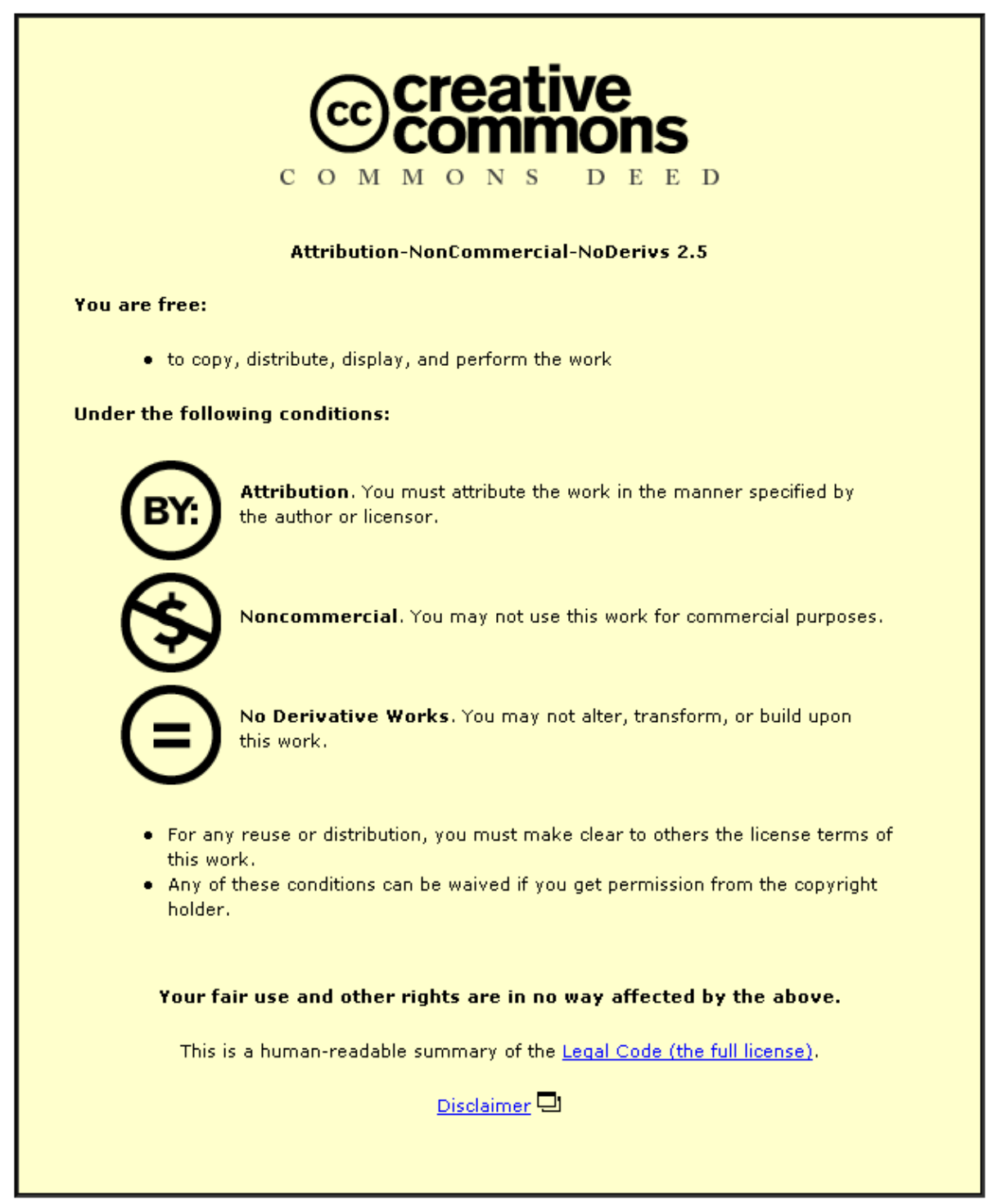

For the full text of this licence, please go to: http://creativecommons.org/licenses/by-nc-nd/2.5/ 


\title{
PARAMETERISING INTERNAL CAMERA GEOMETRY WITH FOCUSING DISTANCE
}

\author{
ENOC SANZ-ABLANEDO (enocsanz@unileon.es), \\ Universidad de León, Spain \\ JIM H. CHANDLER (j.h.chandler@lboro.ac.uk), \\ RENE WACKROW (r.wackrow@lboro.ac.uk) \\ Loughborough University, $U K$
}

\begin{abstract}
A study on the variation of internal camera geometry (principal distance, principal point position and lens distortion parameters) with different focus distances has been conducted. Results demonstrate that variations of parameters are continuous and predictable, allowing a new way to describe internal camera geometry. The classical constant parameters, $c, x_{p}, y_{p}, K_{1}, K_{2}, P_{1}$ and $P_{2}$, are replaced by continuous functions, $c(\gamma), x_{p}(\gamma), y_{p}(\gamma), K_{l}(\gamma), K_{2}(\gamma), P_{1}(\gamma)$ and $P_{2}(\gamma)$, where $\gamma$ is a variable describing the focus position. Incorporation of $\gamma$ as a metadata tag (e.g. Exif header) of a photograph jointly with a parameterised definition of camera geometry would allow full use of the autofocus camera function; enabling maximum effective depth of field, better match of the plane of focus with the object's position and higher reliability. Additionally, conducted tests suggest the parameterised definition of internal geometry could help to locate and correct linear dependences between adjusted parameters, potentially improving the precision and accuracy of calibration.
\end{abstract}

KEYWORDS: camera calibration, focus distance, digital camera, lens distortion, calibration model, close range photogrammetry

\section{INTRODUCTION}

IN RECENT YEARS, IMPROVED RESOLUTION AND SENSITIVITY of photo sensors combined with decreasing costs have enabled the emergence of novel photogrammetric applications using a wide range of non-metric or consumer digital cameras (Fryer et al., 2007). While it is true that the use of cameras not initially designed for metric purposes is allowing photogrammetry to experience a boom, it is also the case that incorrect usage can generate results of low quality. A key constraint is the stability of a camera's internal geometry over 
time (Sanz-Ablanedo et al., 2010), often compromised by technologies included in standard cameras that are not useful to photogrammetrists, including zoom lenses, autofocus, optical stabilisers, sensor stabilisers and image processors (Rieke-Zapp et al., 2009). Most of these technologies can be disabled, depending on the camera, but one feature that always is active, and the photogrammetrist should deal with carefully, is the variable focus distance (from lens to object). A change in the focus distance is achieved by a physical change in the lens configuration, which causes a change in principal distance and lens distortion (Shortis et al., 1998). Therefore conducting photogrammetric work with differing focus distances to that determined during calibration can produce unpredictable results, even in low accuracy work.

Old metric cameras like the original Wild P31 or Zeiss UMK 1318 had a constant principal distance, due to fixed mounted fixed focus lens. This was a necessary design feature because a posteriori calibration of the camera was practicable at that time (Luhmann et al., 2006). Other later systems like the Rollei 6006/6008 Metric system were calibrated in the factory to pre-defined mechanical focusing distance settings. With the advent of the digital age and excluding aerial cameras, it is difficult to find cameras that use fixed lens systems or pre-defined mechanical stops. Even so-called metric cameras like the Rollei d507 Metric or d30 Rollei Metric (manufactured until 2008) was provided with metric calibration for only two electronic focus stops, according to information provided by the manufacturer.

With the demise of the fixed lens and systems of fixed stops (physical or electronic), the trend in the photogrammetric community has been to fix the focus distance (for example by taping the focus ring) normally focussing at infinity or in another position. Sometimes the problem is even ignored, using the autofocus feature regardless of variations to the internal geometry, relying on correlation between interior and exterior orientation.

Setting the focus at infinity in a fixed position is the right choice when objects are at considerable distance, ideally at infinite distance, where rays from the plane of best focus converge on the plane of the sensor. When other object distances or magnification are involved, systematic effects caused by variation within the depth of field occur and extended lens models should be used (Brown, 1971; Fraser and Shortis, 1992). These extended lens models must be established for each particular lens and often are not utilised, by assuming that the magnitude of variation is insignificant (Heng et al., 2010).

An alternative methodology is to work with photographs taken with different focus distances and to use the formulae of Magill (1955). According to Magill, if it is possible to determine the camera distortion parameters at two different focus distances, then it is possible to calculate a set of distortion parameters for any other position of the focusing lens. Although these formulae have been validated experimentally (Brown, 1971; Fryer and Brown, 1986; Wiley and Wong, 1995) they are rarely used. Current self-calibration approaches enable as many calibrations as needed to be performed, with the parameters obtained always being more reliable than those obtained by formulae (Shortis et al., 1998).

The aim of the work presented in this paper is to propose a new way to deal with the variation of focus distance. This incorporates the variability of focus distance as part of the description of the camera's internal geometry. In this new way of modelling a camera, the classical constant coefficients $c, x_{\mathrm{p}}, y_{\mathrm{p}}, K_{1}, K_{2}, P_{1}$ and $P_{2}$ are replaced by continuous functions $c(\gamma), x_{\mathrm{p}}(\gamma), y_{\mathrm{p}}(\gamma), K_{1}(\gamma), K_{2}(\gamma), P_{1}(\gamma)$ and $P_{2}(\gamma)$ where $\gamma$ is a variable that describes 
focus distance. In this work $\gamma$ is the (manual) rotation of the focus ring, although ideally this would be a micro-step controlled by a focus servo motor. Incorporation of $\gamma$ in the photograph's metadata (for example in the Exif header) jointly with a parameterised definition of camera geometry, would allow full use of the autofocus camera function. This would enable maximum effective depth of field, better match of the focal plane with the object's position and higher reliability. Additionally, tests described in this paper suggest the parameterised definition of internal geometry could help to locate and correct linear dependences between adjusted parameters, thus improving the precision and accuracy of calibration.

\section{MATHEMATICAL MODEL FOR DistORTION}

Fig. 1 illustrates the standard parameters describing the internal camera geometry used in this study. The position and distance of the perspective centre and deviations from the central perspective model are described with respect to the image coordinate system, as defined by the pixel array. The origin of the image coordinate system is located in the image plane and ideally coincides with the normal from the perspective centre. Hence, $H^{\prime}$ is the principal point, the intersection of the normal to the image plane from the perspective centre $O^{\prime}$ with image coordinates $x_{0}^{\prime}, y_{0}^{\prime}$ and approximately equal to the centre of the image $M^{\prime}$. The principal distance, $c$, is the distance normal to the perspective centre from the image plane and is approximately equal to the focal length $f$, when focused at infinity. Parameters of functions describing imaging errors are dominated by the effect of the radial-symmetric distortion $\Delta r^{\prime}$ (Luhmann et al. 2006).

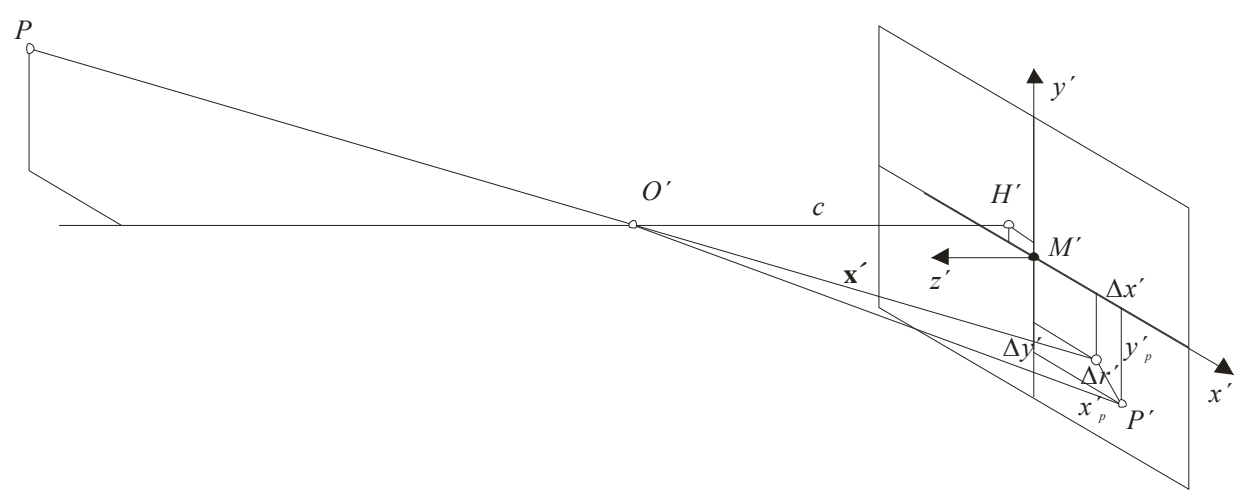

FIG. 1. Interior orientation parameters describing camera geometry (from Luhmann et al., 2006).

When these parameters are known, the (error-free) imaging vector $\mathbf{x}^{\prime}$ can be defined with respect to the perspective centre (and, hence, the principal point):

$$
\boldsymbol{x}^{\prime}=\left[\begin{array}{l}
x^{\prime} \\
y^{\prime} \\
z^{\prime}
\end{array}\right]=\left[\begin{array}{ccc}
x_{p}^{\prime} & -x_{0}^{\prime} & -\Delta x^{\prime} \\
y_{p}^{\prime} & -y_{0}^{\prime} & -\Delta y^{\prime} \\
& -c &
\end{array}\right]
$$


where $x_{p}^{\prime}, y_{p}^{\prime}$ are the measured coordinates of image point $P^{\prime}, x_{0}^{\prime}, y_{0}^{\prime}$ are the coordinates of the principal point $H^{\prime}$, and $\Delta x^{\prime}, \Delta y^{\prime}$ are the axis-related correction values for image errors.

Deviations from the ideal central perspective model, attributable to image errors, are expressed in the form of correction functions $\Delta x^{\prime}, \Delta y^{\prime}$ with respect to the measured image coordinates. In the first instance, measured image coordinates $x_{p}^{\prime}, y_{p}^{\prime}$ are corrected by an offset of the principal point $x_{0}^{\prime}, y_{0}^{\prime}$ :

$$
\begin{aligned}
& x^{\circ}=x_{p}^{\prime}-x_{0}^{\prime} \\
& y^{\circ}=y_{p}^{\prime}-y_{0}^{\prime}
\end{aligned}
$$

Hence, the image coordinates $x^{\circ}, y^{\circ}$ are corrected by $x^{\prime}=x^{\circ}-\Delta x^{\prime}$ and $y^{\prime}=y^{\circ}-\Delta y^{\prime}$. Strictly speaking, the values $x^{\circ}, y^{\circ}$ are only approximations because the corrections $\Delta x^{\prime}, \Delta y^{\prime}$ must be calculated using the final image coordinates $x^{\prime}, y^{\prime}$. Consequently, correction values should be applied iteratively.

Radial (symmetric) distortion constitutes the major imaging error for most camera systems and is attributable to variations in refraction in the lens system. The radial distortion is usually modelled with a polynomial series using the radial distortion parameters $K_{1}$ to $K_{n}$ (Brown, 1966):

$$
\Delta r_{\text {rad }}^{\prime}=K_{1} r^{3}+K_{2} r^{\prime 5}+K_{3} r^{\prime 7}+\cdots
$$

where $r^{\prime}=\sqrt{x^{\circ 2}+y^{\circ 2}}$ is the image radius (the distance from the principal point). Then, the image coordinates are corrected proportionately:

$$
\Delta x_{r a d}^{\prime}=x^{\prime} \frac{\Delta r_{r a d}^{\prime}}{r^{\prime}} \quad \Delta y_{r a d}^{\prime}=y^{\prime} \frac{\Delta r_{r a d}^{\prime}}{r^{\prime}}
$$

Radial-asymmetric distortion, often called tangential or decentring distortion, is mainly caused by decentring and misalignment of the lens components and can be compensated by the following function (Brown, 1966):

$$
\begin{aligned}
& \Delta x_{\text {tan }}^{\prime}=P_{1}\left({r^{\prime}}^{2}+2 x^{\prime 2}\right)+2 P_{2} x^{\prime} y^{\prime} \\
& \Delta y_{\text {tan }}^{\prime}=P_{2}\left({r^{\prime}}^{2}+2 y^{\prime 2}\right)+2 P_{1} x^{\prime} y^{\prime}
\end{aligned}
$$

The individual terms used for modelling the imaging errors of typical photogrammetric imaging systems can be summarised as follows:

$$
\begin{aligned}
& \Delta x^{\prime}=\Delta x_{\text {rad }}^{\prime}+\Delta x_{\text {tan }}^{\prime} \\
& \Delta y^{\prime}=\Delta y_{\text {rad }}^{\prime}+\Delta y_{\text {tan }}^{\prime}
\end{aligned}
$$

\section{EXPERIMENTAL DESIGN}

\section{Materials}

All photographs used in the study described in this paper were taken with a digital single lens reflex (DSLR) Canon EOS 40D camera equipped with a Canon EF $24 \mathrm{~mm} \mathrm{f/2 \cdot 8}$ lens. The Canon EOS 40D has a CMOS (complementary metal oxide semiconductor) sensor of $10 \cdot 1$ Megapixels with a $5 \cdot 7$ microns nominal pixel size. Focus control is achieved using a 9-point TTL (through the lens) CMOS sensor (Askey, 2007). 
The Canon EF 24mm f/2.8 lens has a nominal single focal length of $24 \mathrm{~mm}$ and a diagonal angle of view of $59^{\circ}$. The aperture range is from $f / 2 \cdot 8$ to $f / 22$, and the specified minimum focus distance is $0 \cdot 25 \mathrm{~m}$. The lens construction is comprised of 10 elements in 10 groups and its weight is $270 \mathrm{~g}$. This lens uses "rear focusing” in which focusing groups are located behind the aperture position towards the sensor surface (Fig. 2). With this approach the lens can be designed with a one-piece construction, resulting in improved rigidity and consequent geometric stability. Also, the lens system can be made more compact, providing the opportunity for a lighter design.

All photographs were taken without flash and in aperture priority mode. The aperture chosen was $\mathrm{f} / 2 \cdot 8$, in order to reduce exposure times below $1 / 100 \mathrm{~s}$, using an ISO 250 sensitivity setting. A low JPG compression option was adopted and the photographs were acquired in neutral mode, retaining default values controlling the inbuilt image processing features (sharpness, contrast, saturation, colour tone).

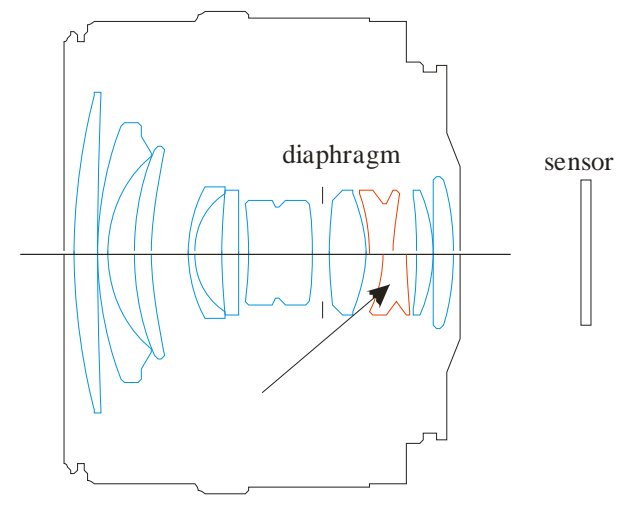

FIG. 2. Internal configuration of the lens used in this work. The arrow identifies the focusing group.

The variation in the internal geometry of the camera with focus distance was studied using 34 calibrations performed with 34 different and progressive changes to the position of the focusing lens. Principal distance, principal point position, two radial distortion parameters and two decentring distortion parameters were recovered. Control of focus position was performed with the notches on the manual focus ring, each being separated by an angular distance of $2 \cdot 5^{\circ}$. Calibrations 32 and 34 were carried out at intermediate positions between notches, since variations close to the infinite settings are greater. Each of the 34 calibrations was performed with sets of photographs taken at different distances from the field of calibration, to ensure that the calibration midfield remained in sharp focus for all images. To calculate the optimal distance for each calibration, the autofocus feature was used, utilising nine focus points. Thus, with the lens focused in "macro position" the distance between the projection centre and the centre of the calibration field was almost 15 $\mathrm{cm}$. In the infinity focus position, the distance to the centre of the calibration field was approximately 6 metres. The distance between the camera and the calibration field for each of the 34 calibrations is shown in Fig. 3. Considering that the nominal focal length of the lens was $24 \mathrm{~mm}$, the magnification was between 1:6 and 1:248. 


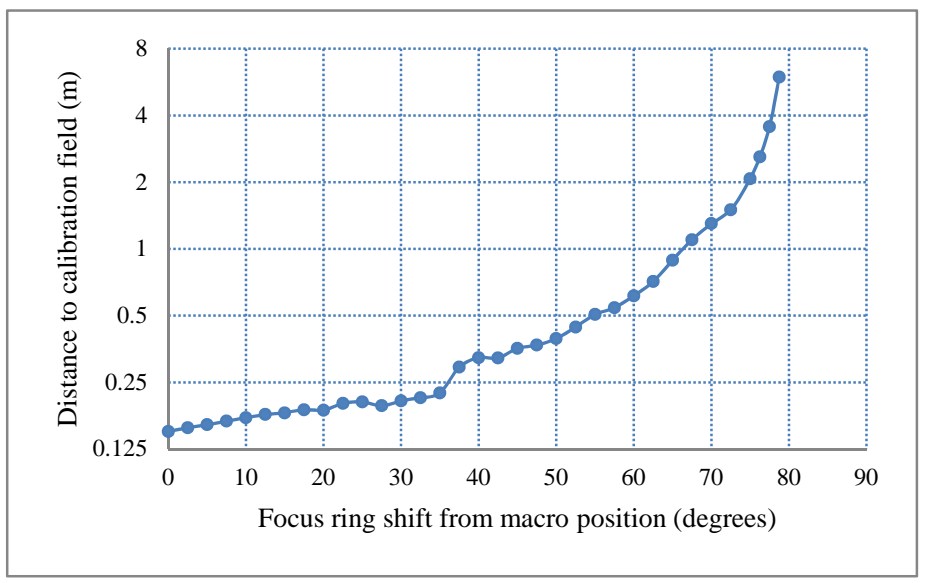

FIG. 3. Approximate distance from camera to the calibration field in all 34 calibrations.

Since the angle of view of the camera does not vary significantly with focus distance, the calibration field size had to be tailored to different distances. With the focus ring close to the macro position and with a distance of approximately $15-18 \mathrm{~cm}$ the field size used for calibration was about $11 \mathrm{~cm}$. At infinity, the calibration field size was about $2 \cdot 58 \mathrm{~m}$. Table I shows the size of the different test fields needed for the calibration.

The first 30 calibrations were achieved using a paper-plotted plane point field (

Fig. 4). The calibration field consisted of 144 black circles of 0.5 to $5 \mathrm{~mm}$ diameter homogeneously distributed in a 12 by 12 grid. In all cases four points had two concentric rings whose discontinuities represent a coding system that allowed automatic referencing of homologous points. Sub-pixel detection algorithms were used for detection of the targets in all images.

For calibration field numbers 31 to 34 , where the size of the test array was greater than the maximum paper size available $(1.40 \mathrm{~m})$, a steel wall was used in conjunction with magnetic spherical white targets (Fig. 5). These targets were constructed using a precision spherical plastic ball with a magnetic piece, which allows quick placement on the wall. The positions of the targets were not known precisely, but were distributed evenly across the surface of the test field.

TABLE I. Size of the 16 fields calibration used.

\begin{tabular}{ccc}
\hline Field size $(m)$ & Calibration number & Calibration method \\
\hline $0 \cdot 11$ & $1,2,3,4,5,6,7$ & 1 \\
$0 \cdot 13$ & $8,9,10,11$ & 1 \\
$0 \cdot 17$ & $12,13,14,15$ & 1 \\
$0 \cdot 21$ & $16,17,18,19$ & 1 \\
$0 \cdot 26$ & $20,21,22$ & 1
\end{tabular}


SANZ-ABLANEDO et al. Parameterising internal camera geometry with focusing distance

\begin{tabular}{ccc}
$0 \cdot 33$ & 23,24 & 1 \\
$0 \cdot 41$ & 25 & 1 \\
$0 \cdot 51$ & 26 & 1 \\
$0 \cdot 64$ & 27 & 1 \\
$0 \cdot 80$ & 28 & 1 \\
$1 \cdot 00$ & 29 & 1 \\
$1 \cdot 24$ & 30 & 1 \\
$1 \cdot 49$ & 31 & 2 \\
1.79 & 32 & 2 \\
$2 \cdot 15$ & 33 & 2 \\
$2 \cdot 58$ & 34 & 2 \\
\hline
\end{tabular}

FIG. 4. Plane point field used during calibration 1-30. 


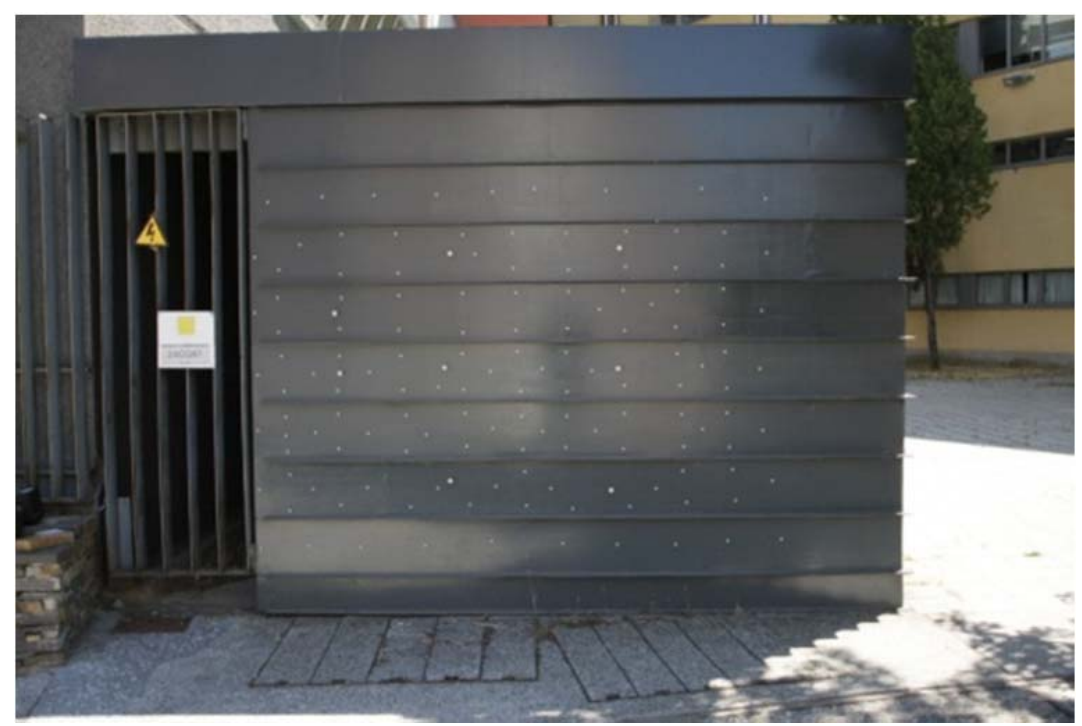

FIG. 5. Point field used in calibrations 31-34.

\section{Method of Camera Calibration}

Determination of internal parameters was carried out using two different procedures. In the first 30 determinations the Photomodeller "Camera Calibration Project" routine was used. In this approach, by assuming that the test field is flat and points are regularly distributed, coordinates of the points could be considered "known" according to an arbitrary reference system. Once target coordinates have been established they could be used as control points and this information entered in the bundle adjustment. This method could be considered a hybrid between self-calibration and field calibration, according to the most widespread scientific nomenclature. In each of the first 30 calibrations, 15 convergent images were taken from five camera stations. At each station, additional images were acquired with the camera rotated around its optical axis by $90^{\circ}$ and $-90^{\circ}$, adopting the usual orthogonal strategy for minimisation of parameter correlation (Shortis et al., 1998).

In calibrations 31-34, the targets were not evenly distributed, so could not be used as control points. In this case the calibration procedure approach adopted in Photomodeller is known as "Full Field Calibration". According to the most widespread scientific terminology used, this method should be considered "self-calibration". In each of the four calibrations, 15 convergent images were acquired from five camera stations. At each station, the camera was again rotated around its optical axis by $0^{\circ}, 90^{\circ}$ and $-90^{\circ}$.

\section{Sensor Size}

The purpose of the study was to analyze the variation of intrinsic parameters with focusing distance. The parameters studied include principal distance, principal point position and the coefficients that model the radial and decentring distortion. However, when calibrating a camera it is usual to consider other parameters to model the difference 
in scale (pixels $/ \mathrm{mm}$ ) and orthogonality between the sensor axes (height and width), (Zhang, 1999). It was not expected that these two variables change with the focusing distance, so it was assumed that these should remain constant. This assumption allows two unknowns to be removed, which reduces linear dependences with other adjusted parameters.

Orthogonality between the sensor axes would seem reasonable considering the stateof-the-art nature and quality of sensor used. The relative scale of the sensor pixels was investigated prior to conducting the main tests. A nominal height of the sensor (14.8082 $\mathrm{mm}$ ) was assumed. 14 calibrations were performed using calibrations fields of variable size between $0.15 \mathrm{~m}$ and $2 \cdot 2 \mathrm{~m}$. Additional parameters in the bundle adjustment included: principal distance, principal point position, two radial distortion coefficients, two decentring distortion coefficients and sensor width. The different widths determined are showed in FIG. 6, which also includes the average value of 14 results (dashed line) and the nominal value of the width of the sensor (continuous line).

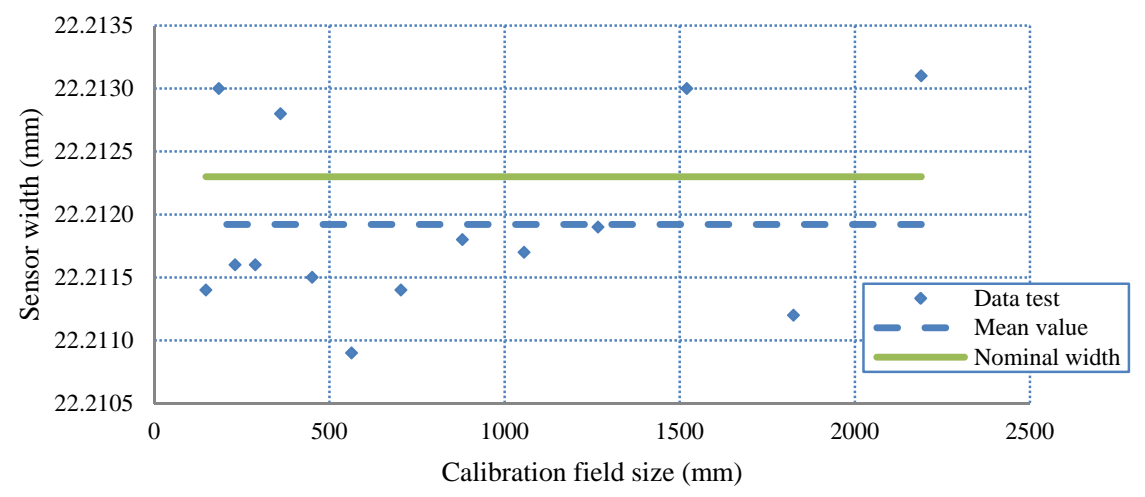

FIG. 6. Results of the test for estimating sensor width.

As expected, there is no obvious trend discernible following use of different focusing distances. Maximum variation between the sensors widths is just $2 \cdot 2 \mu \mathrm{m}$, whereas the standard deviation is below $0.7 \mu \mathrm{m}$, less than $0.003 \%$ of the width of the sensor. The mean width of the sensor eventually used in all subsequent tests differs from the nominal value (3/2 of height) by less than $0 \cdot 4 \mu \mathrm{m}$.

\section{RESULTS AND DISCUSSION}

\section{Principal Distance, $c$}

Fig. 7 shows the principal distances, $c$, obtained in the 34 calibrations performed with different focusing distances, the $\mathrm{x}$ axis representing focusing distance. Units are in angular degrees, corresponding to the screw rotation setting. The value 0 corresponds to the macro position, whilst infinity focus value is achieved with a clockwise rotation of $78 \cdot 7^{\circ}$ looking at the camera from the rear. To prevent (or minimise) mechanical backlash or hysteresis in 
the adjustment of the lens elements, each of the positions of the focussing ring was achieved through a rotation relative to the macro position. Computed principal distances are represented along the y axis.

As perhaps expected, Fig. 7 demonstrates a near perfect linear relationship with rotation of the focus ring. Only a few calibrations results differ slightly from linearity: two close to the macro position with one when focusing at infinity. Deviations close to the macro position may be due to correlation with other parameters introduced into the bundle adjustment. It should be noted first that calibrations achieved close to the macro position involves distances of just 15 to $20 \mathrm{~cm}$. Secondly, when the focus is fixed at such short distances and diaphragm aperture is maximised (f/2.8), the depth of field is drastically reduced, making it almost impossible to obtain clear images of the entire calibration field. This is particularly difficult for images using an oblique perspective, where the best focus plane is located in the centre of the calibration field and outlying points appear slightly blurred. It is difficult to obtain precise measurements for blurred targets and this can cause calibration problems. Finally, some mechanical backlash or hysteresis can occur. The second slight deviation from linearity is observed in the calibration performed with the focus at infinity. On this occasion, with the distance between camera and calibration field of $6 \mathrm{~m}$, it may be insufficient to achieve sharp images using an infinity setting. Regardless of these two points correlation is clear, as demonstrated by a coefficient of determination, $\mathrm{R}^{2}$ above 0.999 , indicating an excellent fit of the regression line with the data.

The second observation to be considered in Fig. 7 is the significant maximum variation of the principal distance $(>3 \mathrm{~mm}$ ) for a lens whose nominal focal length is $24 \mathrm{~mm}$. This equates to changes in the principal distance of up to $12 \cdot 5 \%$.

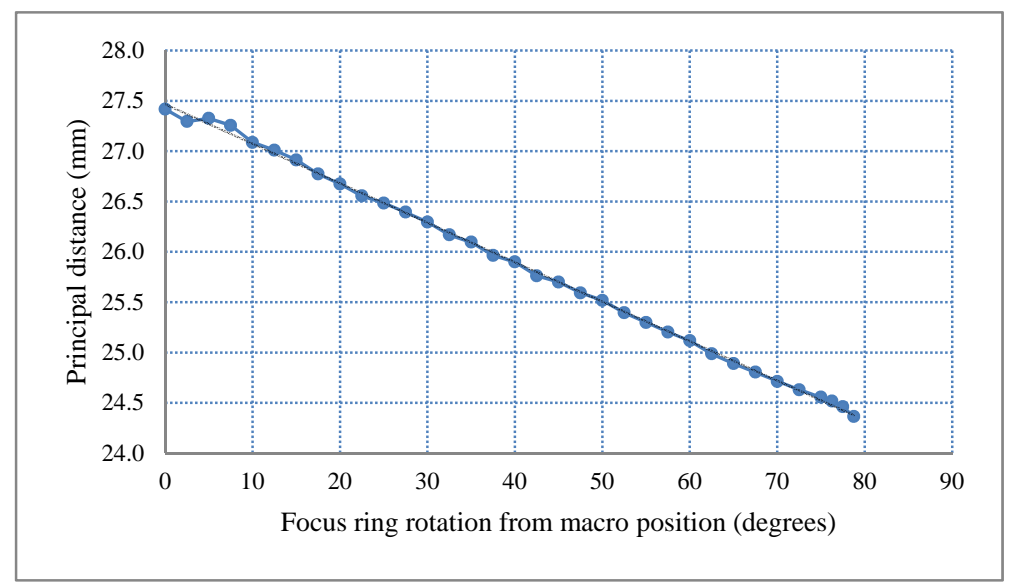

FIG. 7. Variation of principal distance with focusing distance.

\section{First Distortion Radial Coefficient, $K_{I}$}

Fig. 8 shows the first radial distortion coefficient $\left(K_{1}\right)$ obtained for the 34 calibrations performed with different focusing distances. A clear progression or trend is detectable, although in this case the relationship with the rotation of the focus ring is certainly not linear. It can also be seen that the values obtained at short distances have more variation 
than those obtained using a larger test field. The change in depth at long distances is smaller than the depth of focus, whereas at close range the depth of focus will be smaller than the variation in depth of the test field. This results in out of focus images of targets and subsequent variations in the target locations due to aberrations in the target images.

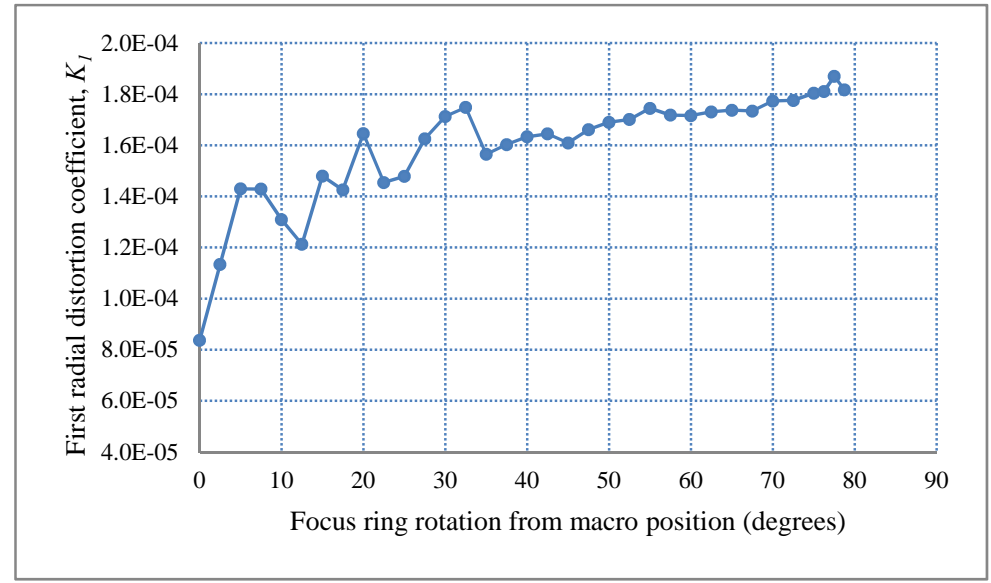

FIG. 8. Variation of first radial distortion parameter $\left(K_{1}\right)$ with focusing distance.

\section{Parameterisation of the Principal Distance and the First Parameter of Radial Distortion}

The values shown in Fig. 7 and Fig. 8 were obtained in a bundle adjustment which simultaneously estimates the position and orientation of each of the 15 photographs, the principal distance, principal point position, two radial distortion coefficients and two decentring distortion coefficients. The various unknowns introduced in the bundle adjustment are not fully independent a there is some degree of correlation between different parameters (Granshaw, 1980). In an attempt to reduce linear dependencies between adjusted parameters, "ideal" or "theoretical" values were calculated for the principal distance $(c)$ and for the first radial distortion coefficient $\left(K_{1}\right)$. The theoretical values of $c$ were calculated using an equation obtained using a linear regression of experimental values, while the theoretical values of $K_{1}$ were calculated with the equation obtained from a polynomial regression of degree two. FIG. 9 shows the new fitted values of $c$, while FIG. 10 shows both the experimental values and the fitted values of $K_{1}$. The "theoretical" values of $c$ and $K_{l}$ were then introduced as fixed values in a new (second) bundle adjustment, in which new values of other parameters and coefficients were obtained. 


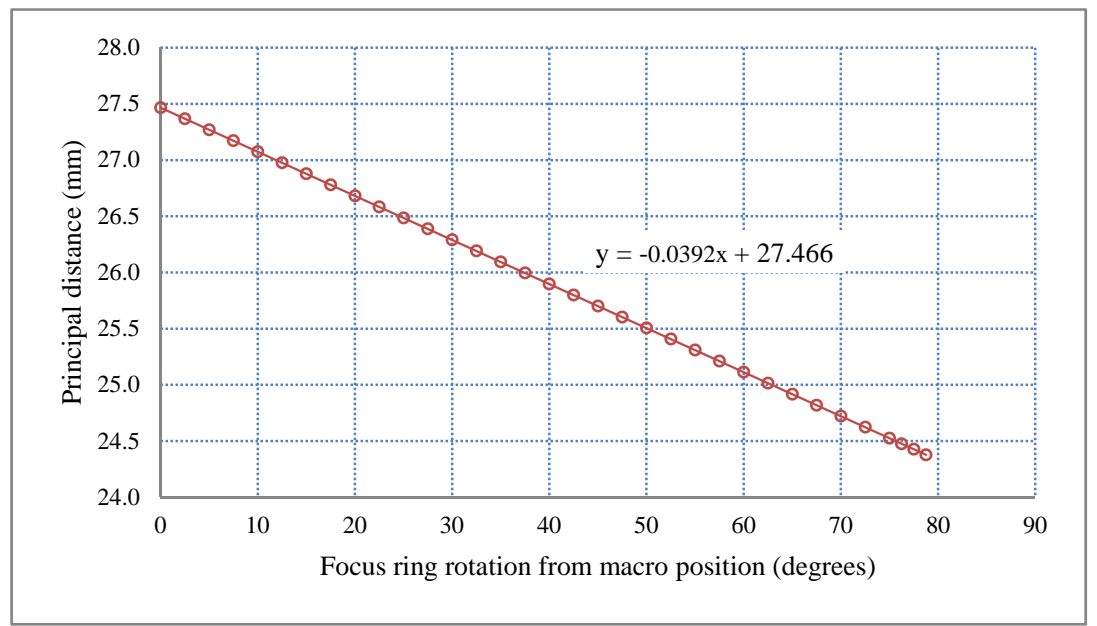

FIG. 9. “Ideal” values for principal distance.

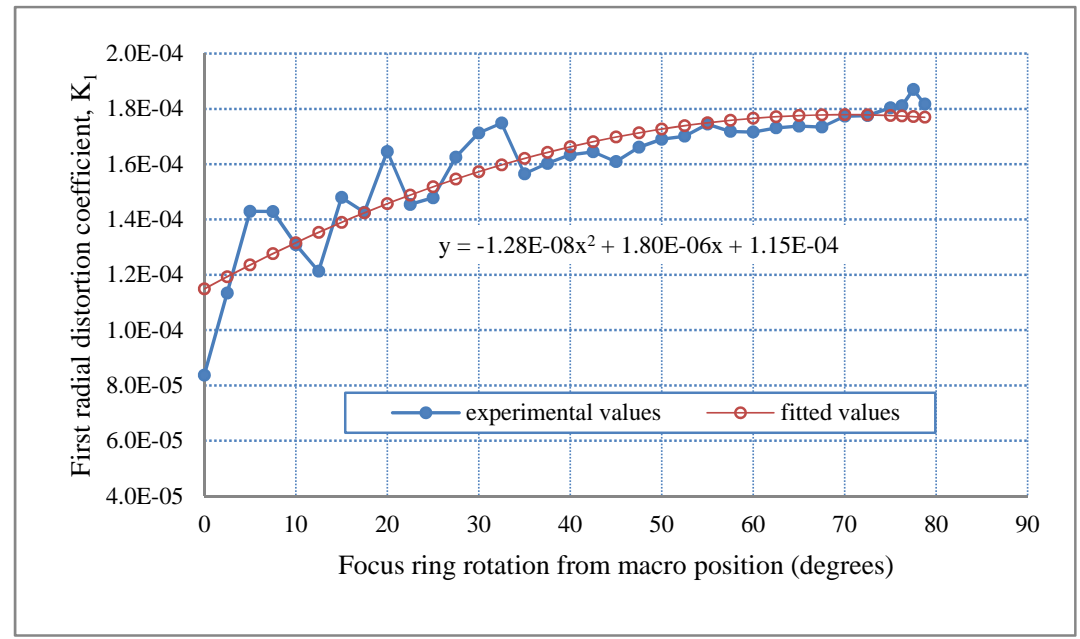

FIG. 10. "Ideal" and experimental values for the first radial distortion coefficient.

\section{Second Distortion Radial Parameter, $K_{2}$}

Fig. 11 shows the variation of the second radial distortion parameter $\left(K_{2}\right)$ with different focusing distances. Blue circles represent the values obtained in the first bundle adjustment, in which all internal geometry parameters were freely estimated. The red squares represent values obtained in the second bundle adjustment, after setting "theoretical" values of principal distance and the $K_{1}$ radial distortion parameter.

Both series show a clear trend of decline, whilst the red square series also demonstrate a smoothed appearance with fewer peaks. A second-degree polynomial curve was fitted to the experimental data derived from the second bundle adjustment, achieving a $\mathrm{R}^{2}$ value of 
$0 \cdot 76$. This more consistent and predictable behaviour suggests that using "ideal” values of $c$ and $K_{1}$ could have reduced the level of dependence between $K_{1}$ and $K_{2}$. A new seconddegree polynomial curve was fitted to the new values of $K_{2}$ obtained in the second adjustment bundle. With the equation of this curve, new theoretical values of $K_{2}$ were calculated, introducing them into a new (third) bundle adjustment.

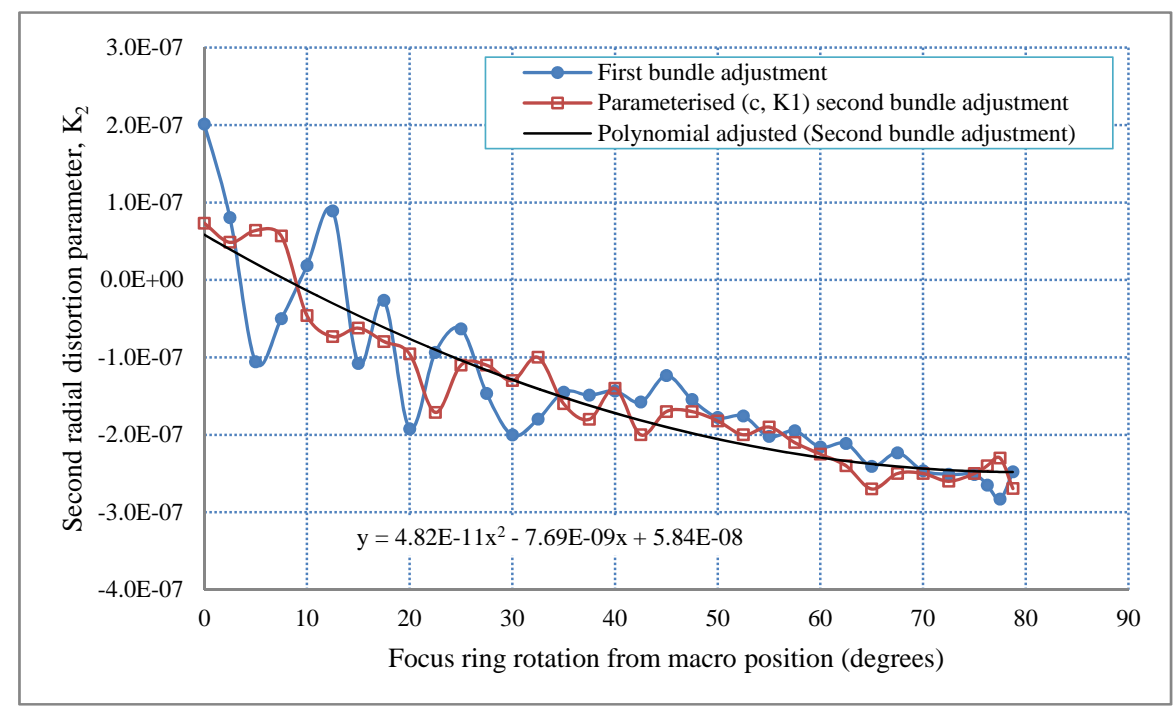

FIG. 11. Variation of the second distortion parameter $K_{2}$.

\section{Principal point position}

FIG. 12 shows the variation of the principal point $x$-component offset with the different focusing distances. Fig. 13 shows the variation of the y-component principal point offset with the different focusing distances. Both figures demonstrate the parameters obtained in the three bundle adjustments; blue circles show the values obtained in the first bundle adjustment, which estimated all internal geometry parameters freely. Red squares show the values obtained after setting "theoretical” values of principal distance and the first radial distortion parameters. Finally green rhombuses represent the values obtained after setting "theoretical" values for the principal distance and first and second radial distortion parameters. Again the data for the third bundle adjustment demonstrate reduced variability with fewer peaks, especially in the case of the x-component which increases the $\mathrm{R}^{2}$ value from $0 \cdot 52$ to $0 \cdot 76$, in the fitting of a new polynomial curve.

Fig. 14 provides another representation, relating to the axes of the sensor, of the principal point positions obtained in the third bundle adjustment. Although the values show high dispersion, there is a clear trend indicated by the arrow in Fig. 14. The maximum range for the variation of the principal point is $60 \mu \mathrm{m}$ in the $\mathrm{x}$ direction and 90 $\mu \mathrm{m}$ in the $\mathrm{y}$ direction. The maximum variation in the polynomial fitting curves are reduced to maximum of $25 \mu \mathrm{m}$ for both $\mathrm{x}$ and $\mathrm{y}$.

With the equations of the fitted curves, new theoretical positions of the principal point were calculated. These theoretical values were introduced in a fourth bundle adjustment 
which estimated, in addition to the positions and orientations of the cameras, decentring distortion parameters $P_{1}$ and $P_{2}$.

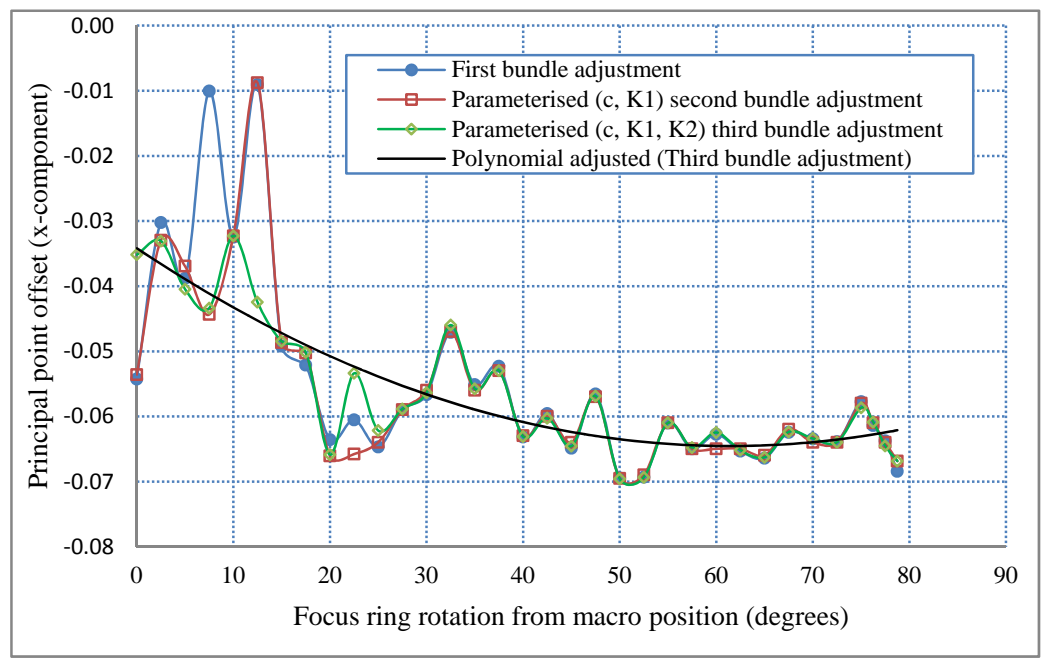

FIG. 12. Variation of principal point offset (x-component) with focusing distance.

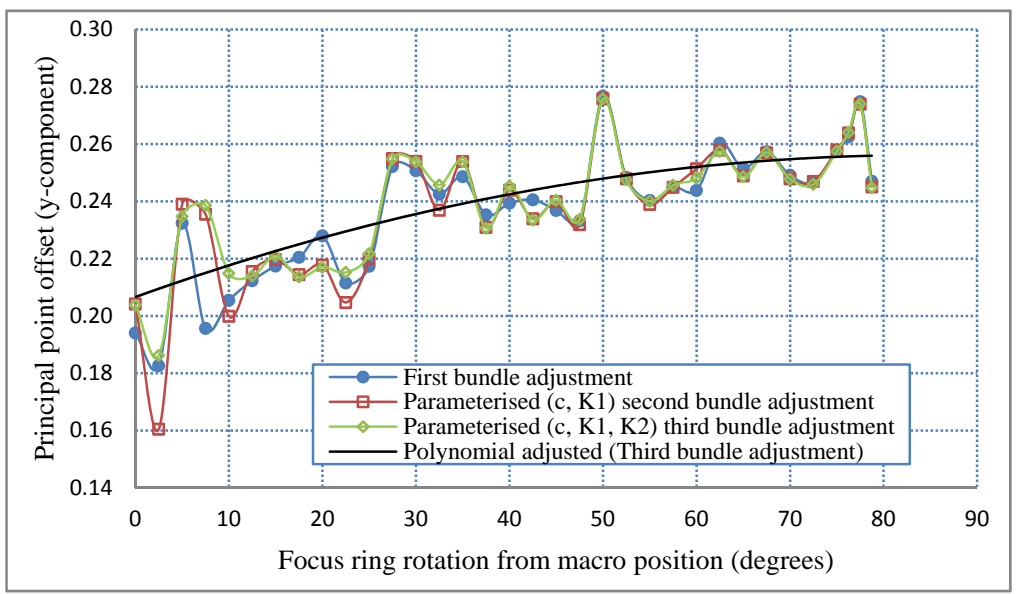

FIG. 13. Variation of principal point offset (y-component) with focusing distance. 


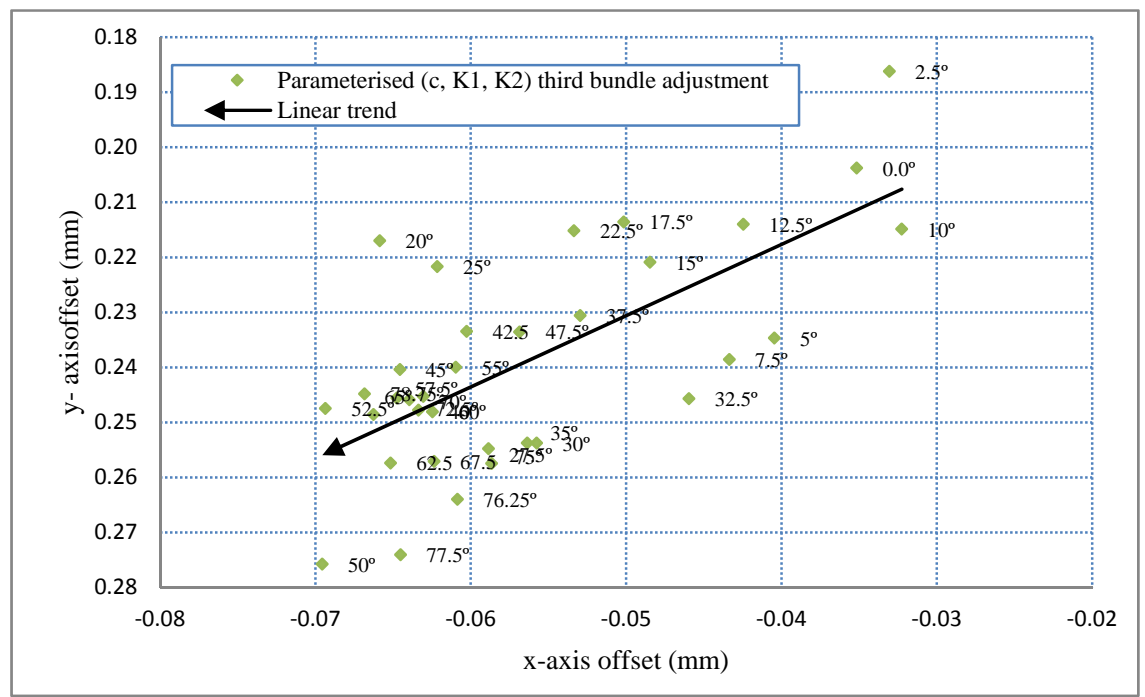

FIG. 14. Variation of principal point position with focusing distance.

\section{Decentring Distortion Parameters}

Fig. 15 shows the variation of the first decentring distortion parameter, $P_{1}$, with different focusing distances, whereas Fig. 16 shows the variation of the second decentring distortion parameter, $P_{2}$. Circles represent values from the bundle adjustment where all parameters $\left(c, x_{\mathrm{P}}, y_{\mathrm{P}}, K_{1}, K_{2}, P_{1}\right.$ and $\left.P_{2}\right)$ are estimated. Squares represent values from the second bundle adjustment where $c$ and $K_{1}$ theoretical values were fixed. Rhombuses represent values from the third bundle adjustment where $c, K_{1}$ and $K_{2}$ theoretical values were fixed. Finally, crosses represent values from the fourth bundle adjustment in which $c$, $K_{1}, K_{2}, x_{\mathrm{p}}$ and $y_{\mathrm{p}}$ theoretical values were fixed.

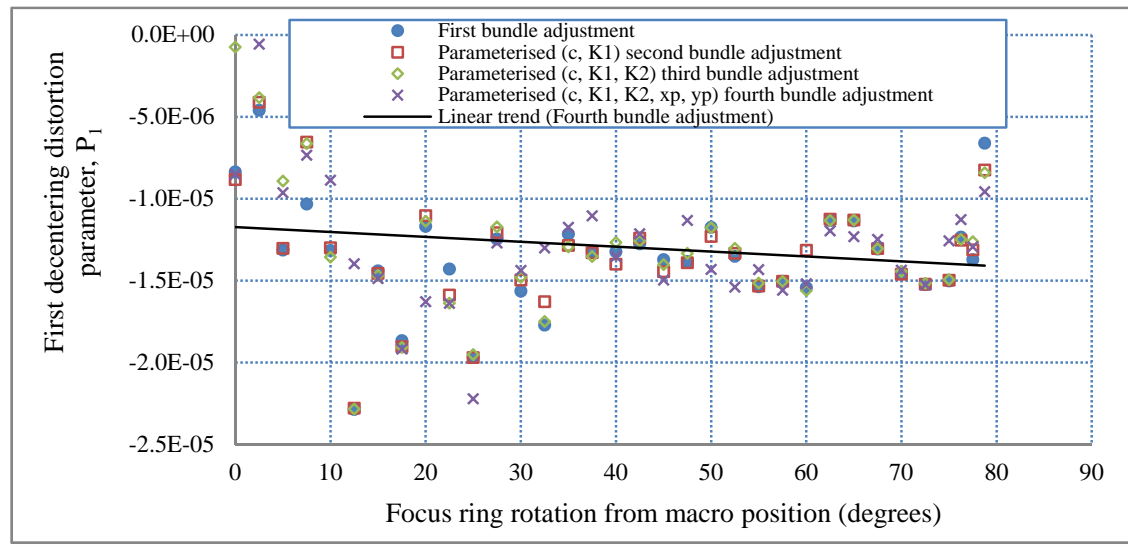

FIG. 15. Variation of first decentring distortion parameter with focusing distance. 
Table II shows $\mathrm{R}^{2}$ values obtained by fitting a linear function to the four series. It can be seen that the $\mathrm{R}^{2}$ value is much improved when increasing use is made of adjusted theoretical values, both in $P_{1}$ and $P_{2}$. This means that the values show a clear trend with less dispersion, suggesting once again that use of theoretical or parameterised values could contribute to the decline of linear dependencies or correlation between adjusted parameters.

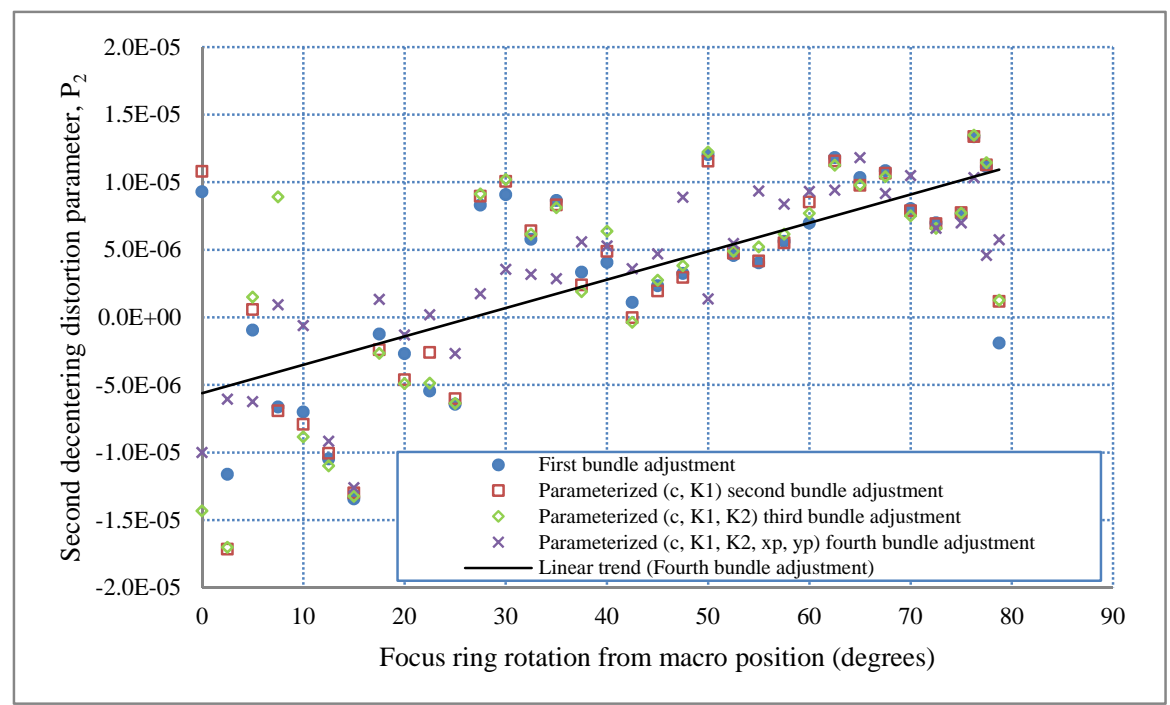

FIG. 16. Variation of second decentring distortion parameter with focusing distance.

Table II. $\mathrm{R}^{2}$ values from adjusting the $P_{1}$ and $P_{2}$ series to a linear equation

\begin{tabular}{ccc}
\hline & $\mathrm{R}_{P 1}^{2}$ & $\mathrm{R}_{P 2}^{2}$ \\
\hline 1st bundle adjustment & 0.0004 & 0.423 \\
2nd bundle adjustment & 0.0008 & 0.427 \\
3rd bundle adjustment & 0.0025 & 0.486 \\
4th bundle adjustment & 0.0037 & 0.641 \\
\hline
\end{tabular}

\section{DISCUSSION}

The correlation between internal camera geometry and distance to the object has been known for a long time. By the middle of last century Magill (1955) derived and experimentally verified a formula which accounts for the variation of radial distortion with changing focus distances. Magill's formula, modified by Brown (1971), accounted only for distortion of points within the particular object plane for which the lens was focussed. It 
did not precisely account for the distortion of other, less sharply focussed, points within the photographic field. Although Magill's formula has been validated experimentally (Brown, 1971; Fraser, 1980; Fryer and Brown, 1986; Wiley and Wong, 1995) it is rarely used (Shortis et al., 1998). There are several reasons for this. Firstly, current self-calibration approaches enable as many calibrations as needed to be performed and parameters obtained in such calibrations will always be more reliable than those obtained by formulae (Shortis et al., 1998). Secondly, due to the desire to maintain camera geometry, it is very common practice to fix the focusing lens (normally to infinity). Finally, there is perhaps only limited recognition that changes occur in a camera's internal geometry with different focusing distances (Al-Ajlouni and Fraser, 2006).

Working with a fixed position of the focus lens creates many problems. Physically restraining the focus ring carries the risk of changing the alignment of the lenses, especially when the focus ring is at one end of the lens. This solution is clearly impracticable for cameras that have no focus ring. Finally, when different objects distances are considered in a fixed focus setting, consideration of the variation of the camera's internal geometry within the photographic field has to be taken into account. Variation of distortion for points distributed throughout the photographic field was studied originally by Brown, (1971), Fryer and Brown (1986) and Fraser and Shortis (1992). Other more recent studies (Dold, 1997; Bräuer-Burchardt, 2007) also concentrated on variations within the photographic field rather than upon different focusing distances. Variation of distortion within the photographic field is complex and has been practicable only for highly specialised systems and in high accuracy applications such as tool inspection and surface characterisation for the aerospace and manufacturing industries (Shortis et al., 1996).

The significant development identified in this paper is to allow free use of the focusing feature of a camera and retrieving, for each focus distance, a different set of internal parameters. There are many advantages with this approach. With freedom of focusing it is possible to locate the focus plane on the object to be measured, so variations inside the photographic field can be minimised and a sharply focused picture is more likely to be obtained. Second, it is now possible to use the full range of focussing distances, enabling pictures to be focused at both infinity and on details very close to the lens. Finally, it is no longer necessary to select higher f-numbers (smaller apertures) to ensure sufficient depth of field, allowing faster exposure times and including the possibility to measure dynamic objects. This freedom in focusing may be of interest not only in very close range photogrammetry, where depth of field may be more limited, but also in industrial photogrammetry or heritage work which may require capturing detail at very close range.

According to Magill, the calculation of radial distortion coefficients at different focusing distances requires the nominal focal length to be constant (Atkinson, 1996). Consequently, changes in the light paths are modelled only by changes in the parameters of radial distortion. However, focal length and principal distance agree only when the camera is focused at infinity; when the lens is refocused, principal distance changes should be taken into account. In this study, changes in the principal distance and in the principal point position, plus distortion parameters, have been considered, demonstrating significant variation. This therefore illustrates the need to also model ray paths more accurately by taking into account these parameters explicitly.

Parameters obtained with different focusing distances show that parameter variation was both progressive and predictable. Different linear and polynomial fits were derived, 
thus obtaining functions that can extract the different sets of parameters for any focusing distance. However, not all parameters showed the same initial uniformity. Principal distance $(c)$ and first radial distortion parameter $\left(K_{1}\right)$ demonstrated a more predictable behaviour. Based on this, and once calculated theoretical values of $c$ and $K_{1}$ were fixed, a new bundle adjustment was made in which additional parameters were obtained. With these new values assigned, further bundle adjustments were repeated to complete the acquisition of all remaining parameters. With this methodology, variations in the parameters were reduced, which could be interpreted as a reduction of linear dependence between them.

\section{CONCLUSIONS}

In this study, variations of internal camera orientation parameters with focusing distance have been successfully modelled, supporting the hypothesis that changes are continuous and predictable. It is therefore no longer necessary to set the focus lens in a fixed position and apply complex camera model extensions to correct camera model variations with the depth of field. Now each photo can be obtained with the optimum desired focus setting and an appropriate correction applied directly and explicity. If focus setting were recorded as a metadata tag in the header information of a photograph, then full benefit would be obtained for spatial measurement.

Additionally, it has been shown that parameterisation of the variables that define the internal geometry of camera can help detect and correct linear dependencies or correlations. The covariance matrix allows only the level of correlation between pairs of adjusted calibrations parameters to be determined. By assuming continuous behaviour it is possible to identify which of them are abnormally high or low due to correlation with other parameters.

\section{REFERENCES}

Al-AJlouni, S. S. and Fraser, C. S., 2006. Zoom-dependent calibration for consumer grade-cameras. International Archives of Photogrammetry, Remote Sensing and Spatial Information Sciences, 36(5): 20-25. ASKEY, P., 2007. http://www.dpreview.com/reviews/canoneos40d/ [Accessed: 1st December 2010].

AtKINSON, K. B. (Ed.), 1996. Close range photogrammetry and machine vision. Whittles Publishing, Caithness, Scotland. 371 pages.

BRÄUER-BURCHARDT, C., 2007. The influence of target distance to lens distortion variation. Modeling Aspects in Optical Metrology, SPIE, 6617: doi:10.1117/12.726110.

Brown, D. C., 1966. Decentring distortion of lenses. Photogrammetric Engineering, 32(3): 444-462.

BRown, D. C., 1971. Close-range camera calibration. Photogrammetric Engineering, 37(8): 855-866

DOLD, J., 1997. Ein hybrides photogrammetrisches Industriemeßsystem höchster Genauigkeit und seine Überprüfung. Doctoral dissertation, Universität der Bundeswehr, Munich, Germany. 137 pages.

FrASER, C. S., 1980. Multiple focal setting self-calibration of close-range metric cameras. Photogrammetric Engineering and Remote Sensing, 46(9): 1161-1171.

FrASER, C. S. and SHORTIS, M. R., 1992. Variation of distortion within the photographic field. Photogrammetric Engineering and Remote Sensing, 58(6): 851-855.

FrYer, J. G., and Brown, D. C., 1986. Lens distortion for close-range photogrammetry. Photogrammetric Engineering and Remote Sensing, 52(1): 51-58.

Fryer, J., Mitchell, H., and Chandler, J. (Eds.), 2007. Applications of $3 D$ measurement from images. Whittles Publishing, Caithness, Scotland. 304 pages. 
GRANSHAW, S. I., 1980. Bundle adjustment methods in engineering photogrammetry. Photogrammetric Record, 10(56): 181-207.

Heng, B. C., Chandler, J. H. and Armstrong, A., 2010. Applying close range digital photogrammetry in soil erosion studies. Photogrammetric Record, 25(131): 240-265.

Luhmann, T., Robson, S., Kyle, S. and HARLEY, I., 2006. Close range photogrammetry: principles, methods and applications. Whittles Publishing, Caithness, Scotland. 510 pages.

MAgiLl, A. A., 1955. Variation in distortion with magnification. Journal of Research of the National Bureau of Standards, 54(3): 153-142.

Rieke-Zapp, D., Tecklenburg, W., Peipe, J., Hastedt, H. and Haig, C., 2009. Evaluation of the geometric stability and the accuracy potential of digital cameras - comparing mechanical stabilisation versus parameterisation. ISPRS Journal of Photogrammetry and Remote Sensing, 64(3): 248-258.

SAnz-Ablanedo, E., Rodríguez-PÉrez, J. R., Armesto, J. and Álvarez TABOAdA, M. F., 2010. Geometric stability and lens decentering in compact digital cameras. Sensors, 10(3): 1553-1572.

SHORTIS, M. R., RoBSON S. and SHORT, T., 1996. Multiple focus calibration of a still video camera. International Archives of Photogrammetry and Remote Sensing, 31(5): 534-539.

SHORTIS, M. R, RoBSON, S. and BEYER, H. A., 1998. Extended lens model calibration of digital still cameras. International Archives of Photogrammetry and Remote Sensing, 32(5): 159-164.

WilEY, A. G. and WONG, K. W., 1995. Geometric calibration of zoom lenses for computer vision metrology. Photogrammetric Engineering and Remote Sensing, 61(1): 69-74.

ZHANG, Z., 1999. Flexible camera calibration by viewing a plane from unknown orientations. Proceedings of the Seventh IEEE International Conference on Computer Vision, 1: 666-673.

\section{Résumé}

Les variations de géométrie interne d'une caméra (distance principale, position du point principal et paramètres de distortion de la lentille) ont été étudiées pour différentes distances focales. Les résultats montrent que les variations de ces paramètres sont continues et prévisibles, ce qui offre une nouvelle méthode pour décrire la géométrie interne d'une caméra. Les paramètres constants classiques $c, x_{p}, y_{p}, K_{1}, K_{2}, P_{1}$ et $P_{2}$, sont remplacés par des fonctions continues $c(\gamma), x_{p}(\gamma), y_{p}(\gamma), K_{l}(\gamma), K_{2}(\gamma), P_{l}(\gamma)$ et $P_{2}(\gamma)$, où $\gamma$ est une variable décrivant la position $d u$ point focal. L'intégration, parmi les métadonnées d'une photographie (e.g. en-tête exif), du paramètre $\gamma$ et d'une définition paramétrique de la géométrie d'une caméra, permettrait d'utiliser pleinement la fonction d'autofocus, de maximiser la profondeur de champ effective et d'ajuster au mieux le plan focal sur la position de l'objet, pour une plus grande fiabilité. En outre, les expériences réalisées montrent qu'une définition paramétrique de la géométrie interne permettrait de localiser et de corriger les dépendances linéaires entre les paramètres ajustés et donc d'améliorer la précision et l'exactitude de l'étalonnage.

\section{Zusammenfassung}

Eine Studie, welche die Veränderung der inneren Kamerageometrie (Kammerkonstante, Bildhauptpunkt, Verzeichnung) bei verschieden Fokussierungen untersucht, wurde durchgeführt. Die Ergebnisse demonstrieren kontinuierliche und prognostizierbare Veränderungen der Parameter und ermöglichen die innere Kamerageometrie in einer neuen Weise zu beschreiben. Die klassischen inneren Kameraparameter $c, x_{p}, y_{p}, K_{1}, K_{2}, P_{1}$ und $P_{2}$ werden durch die stetigen Funktionen $c(\gamma), x_{p}(\gamma), y_{p}(\gamma), K_{l}(\gamma), K_{2}(\gamma), P_{l}(\gamma)$ und $P_{2}(\gamma)$ 
ersetzt, wobei die Variabele $\gamma$ die Fokussierungsposition beschreibt. Das Einfügen von $\gamma$ zusammen mit der parametrisierten Definition der Kamerageometrie in die EXIF Information eines Bildes würde die Benutzung der Autofokusfunktion der Kamera zulassen und ermöglicht maximale Ausnutzung der Objekttiefe, bessere Übereinstimmung der Fokussierungsebene mit der Objektebene und grössere Zuverlässigkeit. Zusätzlich durchgeführte Untersuchungen ergaben, dass die parametrisierte Definition der inneren Kamerageometrie das Lokalisieren und Korrigieren der linearen Korrelationen zwischen den berichtigten Parmetern ermöglicht.

\section{Resumen}

Se ha llevado a cabo un estudio sobre la variación de los parámetros internos de cámara (distancia principal, posición del punto principal y los coeficientes de distorsión) con diferentes distancias de enfoque. Tal y como se comprueba en los resultados las variaciones de los parámetros son continuas y predecibles, por lo que se propone una nueva forma de describir la orientación interna de las cámaras donde los parámetros clásicos constantes, $c, x_{p}, y_{p}, K_{l}$, $K_{2}, P_{1}$ y $P_{2}$, se sustituyen por funciones continuas: $c(\gamma), x_{P}(\gamma), y_{p}(\gamma), K_{1}(\gamma), K_{2}(\gamma)$, $P_{1}(\gamma)$ y $P_{2}(\gamma)$ siendo $\gamma$ la variable que describe la distancia de enfoque. La incorporación de $\gamma$ como metadatos en la información de una fotografía junto con una definición parametrizada de la geometría de la cámara permitiría a los fotogrametristas el uso del enfoque automático, consiguiéndose una máxima profundidad efectiva de campo, mejor coincidencia del plano de mejor enfoque con la posición del objeto y una mayor fiabilidad. Además, como se desprende del análisis de los resultados, la definición parametrizada de la geometría interna de la cámara, podría ayudar a localizar y corregir dependencias lineales entre los parámetros ajustados mejorando la precisión y exactitud de las calibraciones. 